\title{
A DIMENSÃO DE INFRAESTRUTURA COMO BASE NA IMPLEMENTAÇÃO DE UM MODELO DE EDUCAÇÃO A DISTÂNCIA PARA O ENSINO SUPERIOR EM ANGOLA
}

\author{
SÃO PAULO/SP MAIO/2018
Gilberto de Almeida Meireles Patrocínio - Unicsul - gilpatrocinio@gmail.com
Ismar Frango Silveira - Unicsul - ismarfrango@hotmail.com
Laura Marisa Carnielo Calejon - Unicsul - lauracalejon@hotmail.com \\ Tipo: Investigação Científica (IC) \\ Natureza: Relatório Final de Pesquisa \\ Categoria: Pesquisa e Avaliação \\ Setor Educacional: EDUCAÇÃO SUPERIOR
}

\begin{abstract}
RESUMO
Este trabalho constitui-se de um recorte de uma tese de doutorado em que o pesquisador elaborou um modelo de Educação a Distância (EAD) para o Ensino Superior em Angola e validou alguns de seus aspectos. Dentre estes, objetiva apresentar os resultados da Dimensão da Infraestrutura, sendo esta a base para a implantação desta modelo de EAD proposto. Destaca-se ainda a ausência da regulamentação para esta modalidade no país. Para saber se o referido modelo é adaptável à realidade de Angola, foi aplicado um curso de formação e capacitação em EAD para elaboração de material didático e estudo dos ambientes em 30 especialistas, dentre estes, professores e engenheiros do projeto ANGOSAT (primeiro satélite angolano), da Universidade Agostinho Neto (UAN) e do Instituto Superior e Tecnologias de Informação (ISUTIC). Esta foi realizada no ISUTIC, e teve como aporte teórico a abordagem de sistêmica de Moore e Kearsley (2013), os Referenciais de qualidade para a Educação Superior a distância no Brasil (2007) e, por fim, as características socioculturais de Angola. Quanto aos instrumentos metodológicos, nos valemos da Pesquisa-Ação com ênfase na Pesquisa Qualitativa e como Coleta de Dados o uso do questionário. Como resultado, constatou-se que, a Dimensão da Infraestrutura é a base ou guia para a implementação do modelo EAD proposto e que $O$ mesmo é adequado à realidade de Angola.
\end{abstract}

Palavras-chave: Angola, Modelo de Educação a Distância, Abordagem Sistêmica, Características socioculturais de Angola, Dimensão da Infraestrutura. 


\section{1 - Introdução}

A Educação a Distância tem sido muito abordada em muitos países em via de desenvolvimento para colmatar ou ao menos reduzir as insuficiências que o ensino presencial apresenta, no que tange à sua demanda, especificamente no número limitado de estudantes. Dessa forma, torna-se imprescindível se pensar na democratização do acesso ao ensino, bem como na massificação dos recursos das Tecnologias de Informação e Comunicação (TICs), visando assim contribuir no desenvolvimento sustentável das nações.

O Ensino Superior (ES) Angola está estruturado por 8 Regiões Acadêmicas (RA), sendo que estão em funcionamento 64 IES (24 públicas e 40 privadas), aproximadamente 300.000 alunos estão matriculados na modalidade presencial, sendo esta a única em funcionamento e, também conta com 8.660 docentes (ANGOLA, 2016). A porcentagem de matriculas de 18 a 24 anos com relação à população é de 2.8\%. (ANGOLA 2014d).

Atualmente, o país possui uma população de 26 milhões de habitantes, sendo que a população economicamente ativa (dos 15 aos 60 anos) corresponde a $60 \%$, isto é, aproximadamente 15 milhões de habitantes. A UNESCO (2009) considera que um estudante universitário está na proporção 100 habitantes. Isso implica dizer que Angola hoje deveria contar com 1,5 milhões de estudantes matriculados no Ensino Superior. Assim, surge a necessidade de se introduzir a EAD neste país. Ainda que em fase inicial, existe certa vontade política visando à viabilização/implementação dessa modalidade de ensino no país. Destaca-se ainda a ausência de regulamentação da mesma, porém, algumas iniciativas têm sido realizadas por parte do governo, como a elaboração do projeto ANGOSAT (primeiro satélite angolano), a rede de mediatecas (ReMa), entre outras, que poderão melhorar os recursos de infraesterutura, tanto física quanto tecnológica. Não obstante, vários pesquisadores angolanos, como no caso deste trabalho, visam buscar soluções para contribuir nessa empreitada de viabilizar a EAD no país, buscando aprimorar os índices educacionais locais.

Cabe citar aqui, os principais desafios que Angola enfrenta diante do uso dessa modalidade (ANGOLA 2011a):

- O índice reduzido de recursos humanos com competências específicas em EAD;

- A credibilidade da EAD, uma vez que a população está somente acostumada com o modelo presencial;

- O elevado investimento financeiro inicial como pré-requisito para a implementação de sistemas EAD; 
- A falta de autonomia do aluno e extrema dependência do professor;

- O acesso restrito às TICs, os seus elevados custos, a competência vulnerável no seu uso, bem como a carência de uma cultura tecnológica, por grande parte da população;

Esses desafios nos possibilitam refletir que as TICs promovem a qualidade da EAD contribuindo assim na melhoria dos processos de interação e de ensino e aprendizagem nos cursos dessa modalidade. Porém, elas não são reduzíveis aos meios de desenvolvimento humano, pois, não oferecem totalmente soluções para problemas mais complexos, como por exemplo, a falta de cultura desta modalidade, a falta de condições materiais, a pouca familiaridade com os recursos tecnológicos por grande parte da população angolana. Os resultados do Censo (ANGOLA, 2014d) indicam que 37,5\% da população utilizam celulares, 9,9\% possuem computadores e 10,2\% têm acesso à Internet.

A experiência que o pesquisador vem adquirindo como docente nas modalidades presencial, semipresencial e a distância na Universidade Cruzeiro do Sul e na Cruzeiro do Sul Virtual, respectivamente, a participação em congressos internacionais de Educação a Distância, para além de ser Membro da Associação Brasileira de Educação a Distância, os vínculos com Angola, terra natal do pesquisador, configuraram o cenário e a motivação para elaboração a proposta de um Modelo de EAD para o Ensino Superior em Angola, na vertente de contribuir na potencialização, expansão e democratização do acesso ao Ensino Superior no referido país.

\section{2 - Referencial Teórico}

Moore e Kersley (2013) definem a EAD como o aprendizado planejado que ocorre normalmente em um lugar diferente do ensino, o que requer comunicação por meio de tecnologias e uma organização institucional. Para melhor abstrair um dado modelo, estes autores argumentam que é essencial compreender a necessidade de uma abordagem sistêmica, sendo que, esta consiste na compreensão do todo a partir de uma análise panorâmica das partes e de como estas interagem entre si. Para estes autores, um sistema de EAD deve abarcar os seguintes componentes: fonte de conhecimento, criação do curso, tecnologias e mídias, interação, ambientes de aprendizado, monitoramento e avaliação, política e gerenciamento.

Não obstante, os Referenciais de Qualidade para a Educação Superior a Distância (BRASIL, 2007) apontam que, devido à complexidade e à necessidade de uma abordagem sistêmica, referenciais de qualidade para projeto de cursos na modalidade a 
distância devem compreender categorias que envolvem, fundamentalmente, aspectos pedagógicos, recursos humanos e infraestrutura. Este documento revela também que, para atender estas dimensões, devem estar integralmente expressos no Projeto Político Pedagógico de um curso na modalidade a distância. Estes referenciais apontam que um sistema de EAD deve abarcar os seguintes componentes principais: Organização curricular, Sistemas de Comunicação, Material didático, Avaliação, Equipe multidisciplinar, Infraestrutura de apoio e Gestão acadêmico-administrativa.

\section{Proposição do Modelo de EAD para o Ensino Superior em Angola: A Dimensão de Infraestrutura}

De acordo com a visão sistêmica de Moore e Kearsley (2013), os Referenciais de Qualidade (Brasil, 2007) e as Características socioculturais de Angola, modelo de EAD para o Ensino Superior em Angola foi estruturado em três dimensões (vide figura1): Dimensão Acadêmica, Dimensão da Gestão e Dimensão da Infraestrutura.

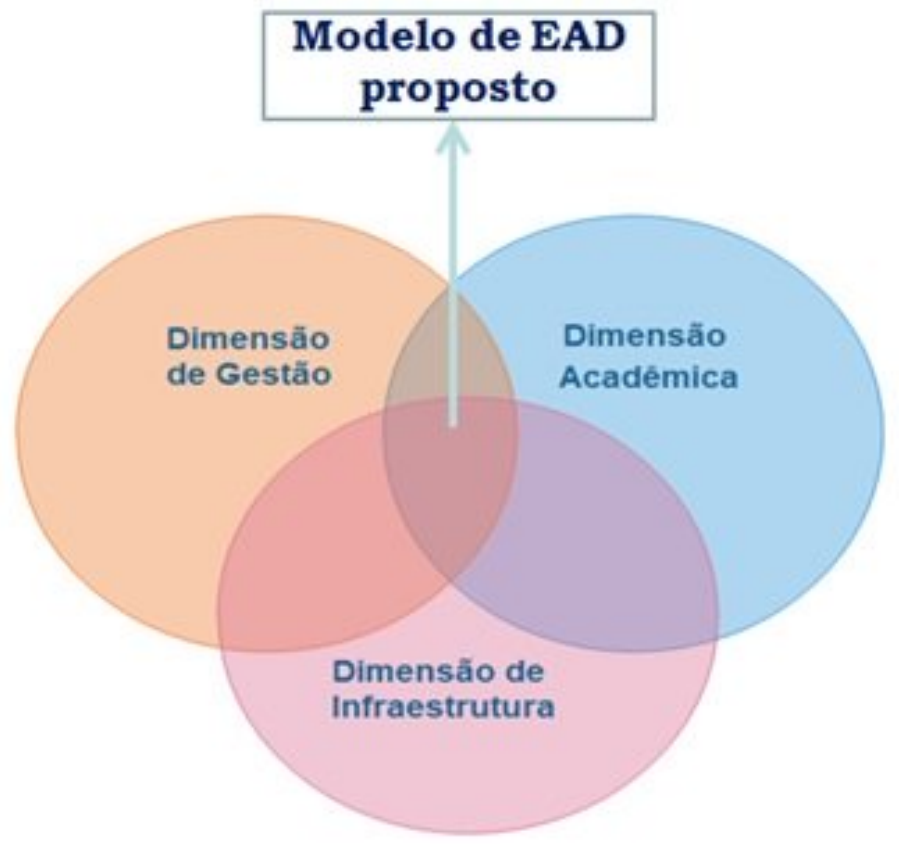

Figura 1- Dimensões do Modelo de EAD proposto por meio da abordagem sistêmica.

Podemos observar na figura 1, que, tais dimensões estão inter-relacionadas, pois, na medida em estas ocorrem, exercem um impacto sobre certas forças no ambiente em que operam, tais como: os ambientes físicos, político, econômico e social. É fundamental compreender esta inter-relação, pois, ao se tratar de qualquer parte do referido modelo, é crucial lembrar que tudo que acontece em uma parte do sistema exercerá efeito nas outras partes. Conforme dito anteriormente, somente será abordada a Dimensão da infraestrutura como delimitação do presente artigo, sendo esta o norte 
para a sustentabilidade do modelo que foi proposto. Esta Dimensão é representada pela figura 2.

INFRAESTRUTURA

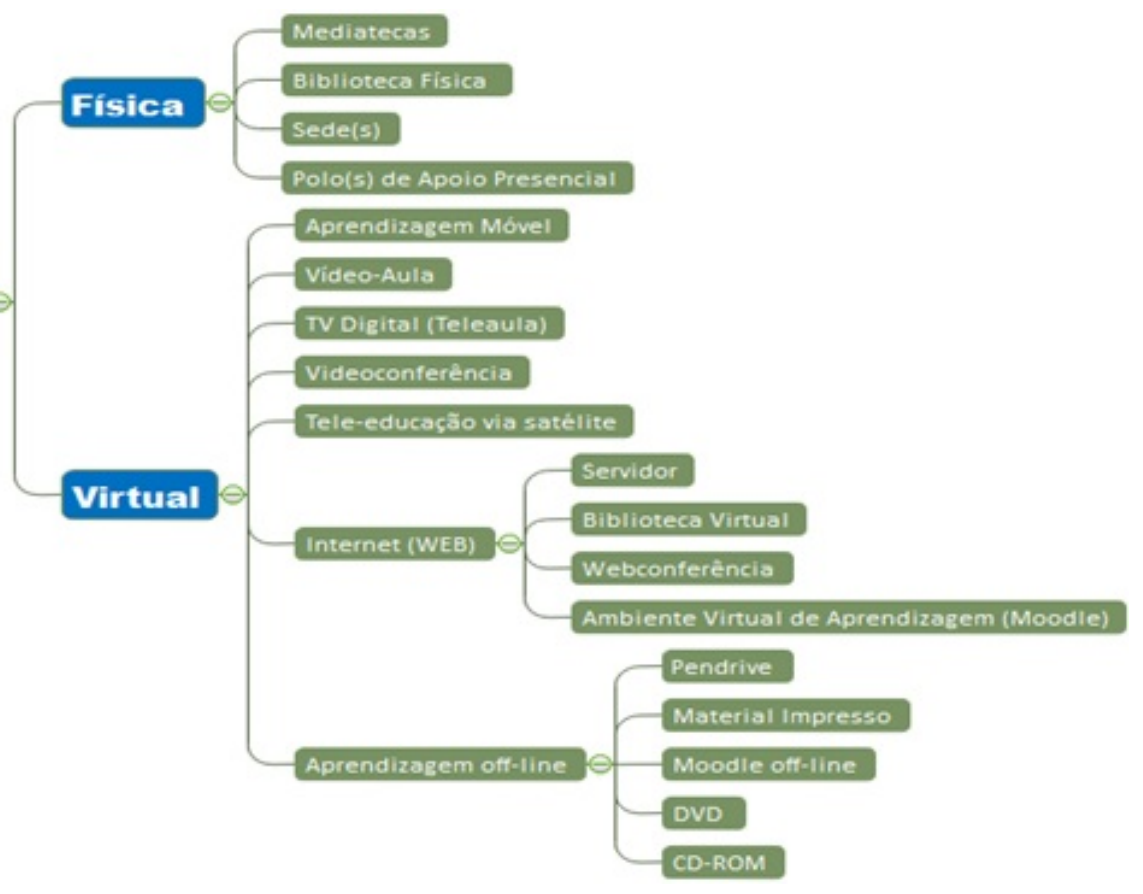

Figura 2- Dimensão da Infraestrutura do Modelo de EAD proposto.

O modelo de EAD proposto tem como norte a infraestrutura (tanto Física, quanto Tecnológica), de acordo com as características socioculturais do país. Este prevê uma Dimensão de Infraestrutura tecnológica estruturada pelos seguintes elementos: Aprendizagem Móvel (m-learnig), Vídeoaula, TV Digital, Videoconferência, Teleeducação (Satélite), Internet com os seguintes serviços: (Biblioteca Virtual, Webconferência, Servidor, Ambiente Virtual de Aprendizagem Moodle) e Aprendizagem Off-line. Prevê também uma Infraestrutura Física com os seguintes componentes: Polos de apoio (secretaria e sala de tutoria), Biblioteca Física e Mediatecas. Destacamos também que somente algumas varáveis do referido modelo foram validadas. Dessa forma, foi aplicado o Curso de formação em EAD: Elaboração de Material Didático e Estudos dos Ambientes Virtuais aos participantes acima mencionados. Reitera-se que esse curso foi realizado no Instituto Superior de Tecnologias de Informação (ISUTIC). 0 curso foi organizado com base no material disponibilizado pela equipe da Cruzeiro do Sul Virtual, que também auxiliou o pesquisador na elaboração do design educacional do referido curso. A pesquisa-ação demonstra o planejamento da validação deste modelo, com destaque na infraestrutura.

\section{3 - A Pesquisa-Ação}


A pesquisa-ação constitui-se como método mais adequado para a resolução do problema considerado como central da pesquisa, ao levantar soluções e propostas de ações correspondentes à resolução de problemas (QUEIROZ, et. al., 2012, p. 279). Com o emprego do método qualitativo (CRESWELL, 2007), objetivou-se detalhar os processos desencadeados durante as fases da pesquisa, problematizando-os metodologicamente e discutindo os desafios e potencialidades decorrentes da operacionalização do método. Constatou-se que a pesquisa-ação possibilitou a apropriação e o envolvimento dos sujeitos implicados na pesquisa; a criação das condições para a validação de algumas variáveis do modelo de EAD proposto, bem como o estabelecimento de novas relações com especialistas angolanos e a ampliação do conhecimento sobre a temática da Educação a Distância. Plano de Ação foi categorizado de acordo com a figura 3 .

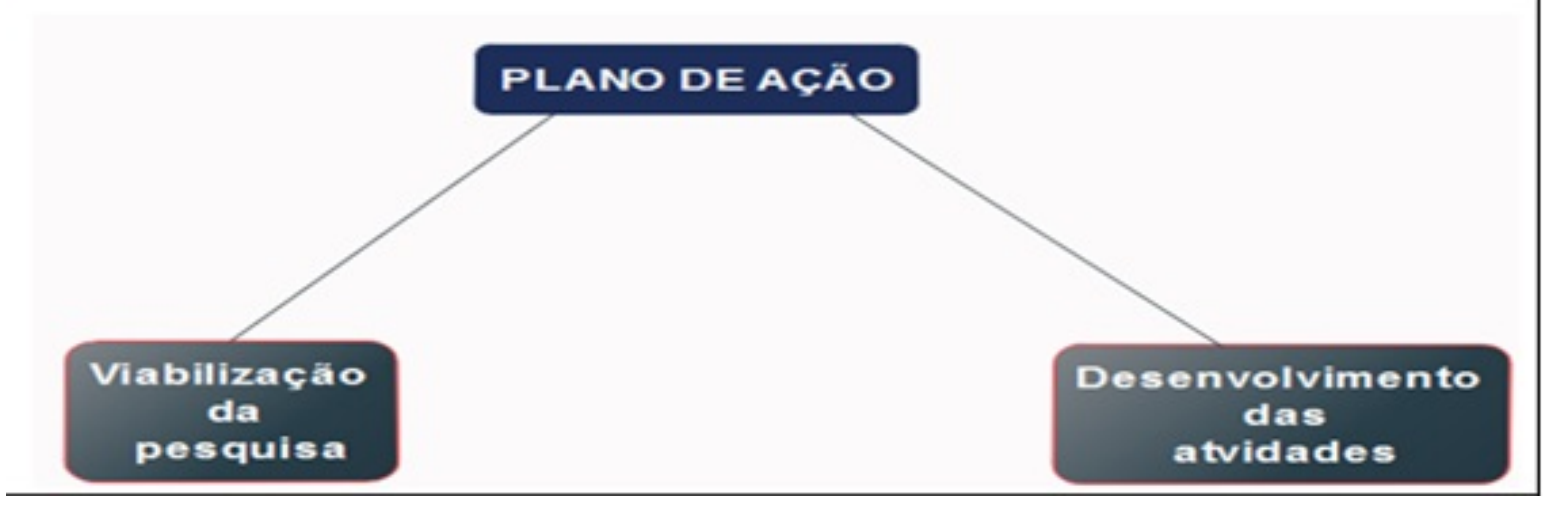

Figura 3 - Plano de Ação.

Para a viabilização dessa pesquisa, o pesquisador teve o suporte do Departamento de tecnologias e infraestrutura do ISUTIC, valendo a pena destacar as seguintes os seguintes itens: Impressão do material didático; Disponibilização de três técnicos de Informática para darem o suporte necessário durante a realização do curso; Disponibilização do maior laboratório do instituto que alberga 30 computadores e 30 lugares, 1 Datashow, 2 ar- condicionados e Internet em ótimas condições; Realização de reuniões com os técnicos de Informática dias antes de um determinado encontro presencial, com o objetivo de preparar o ambiente para a realização do curso, respectivamente; Disponibilização de um Gabinete de trabalho com 1 computador de mesa, Internet 24 horas, 1 Impressora, ar condicionado, onde foi possível o pesquisador se (re)organizar e realizar todas as atividades de planejamento da pesquisa.

Durante a aplicação do curso de Formação e Capacitação em EAD, nos períodos de interação à distância, os participantes realizaram diversas atividades, que, em geral, consistia em ler dos textos das disciplinas; assistir os vídeos; interagir com o tutor por 
meio de fóruns de discussão, para debater questões colocadas; realização de tarefas envolvendo trabalhos colaborativos utilizando a ferramenta Google Docs; leitura do material impresso e digital, no caso da ausência de Internet. Os encontros presenciais consistiam, em geral, em promover debates sobre as indagações colocadas nos fóruns; discussões sobre a validação do modelo de EAD proposto; aulas sobre a avaliação da EAD por meio de fóruns e a inserção de conteúdos na plataforma Moodle. Além disso, outras atividades envolviam o uso de mapas mentais, bem como a realização de tarefas envolvendo trabalhos colaborativos utilizando a ferramenta Google Docs. O planejamento dessas atividades foi imprescindível para que a validação do modelo de EAD proposto ocorresse de forma bem sucedida.

\section{4 - Resultados}

De acordo com Moore e Kearsley (2013), uma forma de examinar as inter-relações entre os componentes em um sistema de EAD consiste em adotar uma técnica comum na modelagem de sistemas, considerando o sistema em termos de entradas e saídas. Dessa forma, para validar o modelo de EAD proposto, aplicou-se o Curso de formação em EAD aos participantes da pesquisa, de modo a se obter os índices de satisfação dos participantes em relação às variáveis do referido modelo submetidas à validação, bem como os resultados apresentados pelos mesmos.

Outro aspecto que muito contribuiu na validação foi considerar o modelo em termos de entradas e saídas. Como entrada considerou-se as variáveis do modelo que foram validadas e abordadas, cujas são as seguintes: a Caracterização dos participantes, a Avaliação, a Interação (aluno-aluno), o Material Didático (interação aluno-conteúdo), a Organização Curricular, a Tutoria presencial (interação aluno-tutor), a Teoria de Aprendizagem, a Internet e Aprendizagem Offline (material impresso e pendrive).

Conforme observado na figura 5, quanto à adequação dos vídeos, a infraestrutura do ISUTIC, bem como a importância da criação de polos de aprendizagem, é possível observar que $100 \%$ dos participantes da pesquisa concordaram. 


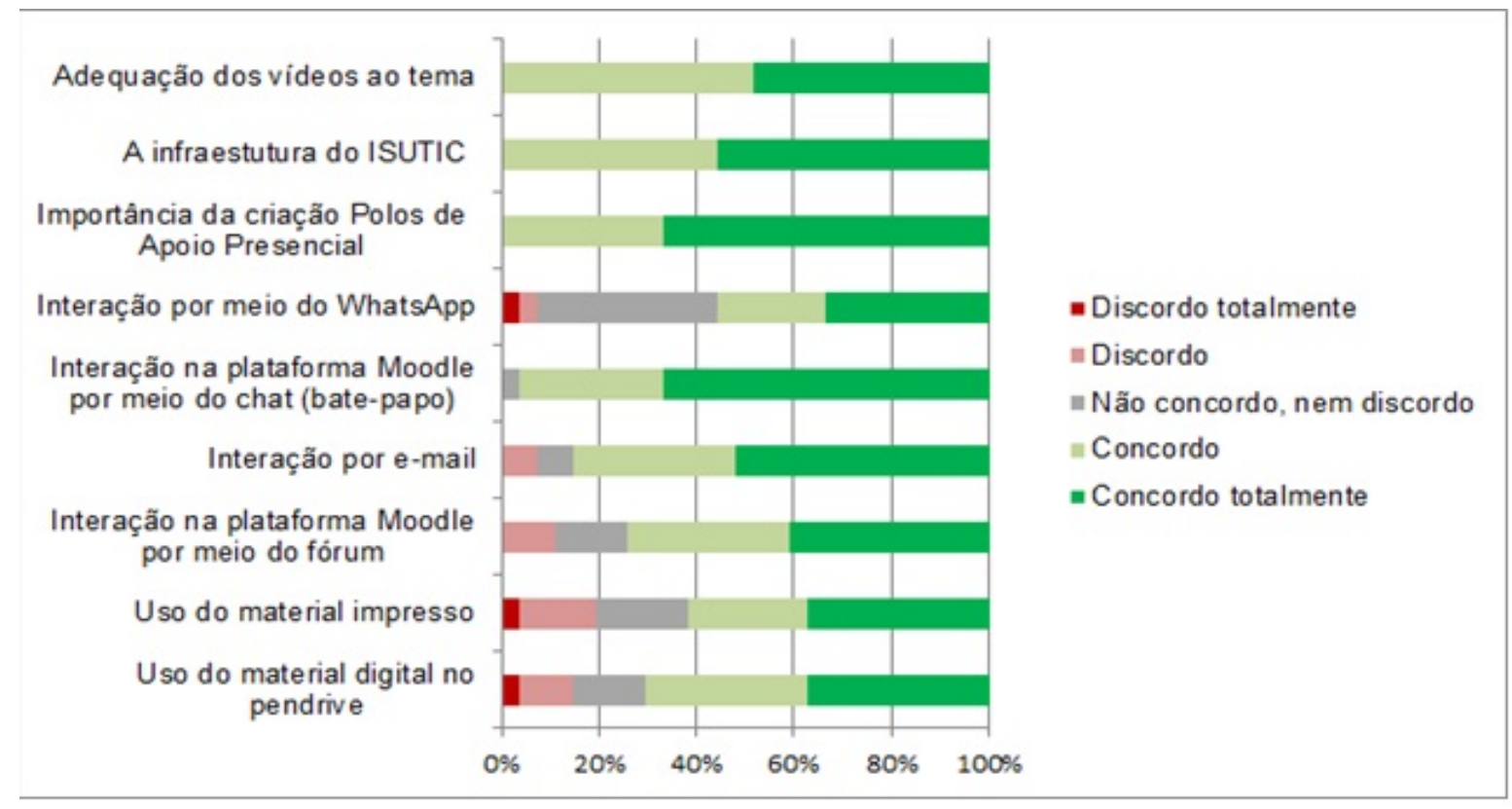

Figura 5 - Resultados dos participantes em relação à Dimensão de Infraestrutura.

Apesar da variável polo não ter sido testada, foi essencial averiguar a percepção dos participantes da pesquisa sobre a importância da criação de polos de aprendizagem para os estudantes. Para o modelo de EAD proposto, sugere-se a criação de polos de apoio presencial em todas as regiões do país e o (re)aproveitamento das redes de mediatecas nacionais, visando a democratização do ensino superior e na massificação das TICs no pais.

No que concerne à tutoria a distância observa-se que, 92\% dos participantes consideram que o processo de tutoria a foi adequado, $4 \%$ ficaram neutros e $4 \%$ discordam. Após o término de cada encontro presencial, os participantes eram notificados sobre quais atividades seriam realizadas a distância, durante o período de vigência de cada disciplina. As mensagens eram enviadas por meio da ferramenta chat da plataforma Moodle.

Observou-se que estes também interagiram com menos frequência no grupo Whatsapp, conforme se pode notar, $55 \%$ concordam, 35\% ficaram neutros, $10 \%$ discordam. No Whatsapp, o grupo interagiu pouquíssimas vezes, pois somente alguns participantes respondiam. Acredita-se que seja devido o fator idade, ou pelo fato de estes não estarem acostumados ou mesmo falta de tempo. Nenhum indicativo de rejeição da ferramenta do Whatsapp foi identificado. Quanto à interação por meio dos fóruns, podese observar que $77 \%$ dos participantes consideram que o uso do fórum é imprescindível, $15 \%$ ficaram neutros e somente $8 \%$ discordaram. Conforme dito anteriormente, a participação do fórum por grande parte dos participantes foi um desafio, devido aos seus 
compromissos laborais. Quanto ao material impresso, conforme o observado na figura $5,61 \%$ considera que o material impresso não foi imprescindível, $19 \%$ ficaram neutros e $20 \%$ discordaram. O material impresso não foi determinante para a realização do curso. No contexto da pesquisa, todos os participantes têm acesso a Internet, a maioria trabalha no projeto ANGOSAT e muitos não usaram material impresso, nem o material no pendrive, ainda que seja um grupo com a faixa etária acima dos 26 anos. Constatase assim, que este grupo possui uma realidade diferente, pois, são engenheiros, mestres e doutores e de bom nível social e econômico. Entretanto, não é possível generalizar, pois, trata-se de um grupo de Luanda (capital de Angola) específico. Para o modelo de EAD proposto, não faz sentido abrir mão do material Offline, mesmo que vários participantes dessa pesquisa não o tenham utilizado.

\section{Considerações Finais}

No entanto, é imprescindível se pensar na flexibilidade do modelo de EAD proposto para diferentes contextos, pois, a obrigatoriedade de certos elementos pode dificultar ou mesmo impedir a implantação de determinados aspectos. Portanto, defende-se que a regulação seja flexível, permitindo modelos distintos e de forma não proibitiva.

Não obstante, constatamos que para o modelo de EAD proposto para o Ensino Superior em Angola, a infraestrutura, tanto física quanto tecnológica, deve ser o ponto central ou de partida, pois, é ela norteia o modelo, sob a visão sistêmica dos seus componentes. Durante a sua validação, constatou-se que o polo de apoio presencial precisa ser bem projetado para garantir efetivamente o pleno desenvolvimento das atividades dos cursos a distância e oferecer condições e serviços adequados e suficientes para atender aos docentes e estudantes em suas expectativas, demandas e necessidades. Destaca-se também, que o (re)aproveitamento das redes de mediatecas nacionais também é imprescindível para a implantação do modelo de EAD proposto. Portanto, é importante buscar reflexões sobre o processo de democratização do acesso Ensino Superior angolano e na massificação do acesso às Tecnologias de Informação e Comunicação. Isso poderá tornar possível a institucionalização e regulamentação da Educação a Distância. Não obstante, é necessário formar quadros com competências específicas nesse ramo, de modo que haja uma verdadeira cultura desta modalidade de ensino.

\section{Referências}

MORAN, J. M. Novas tecnologias e Mediação pedagógica. 19. ed. São Paulo: Papirus, 2012. 
MORAN, J. M. Modelos e Avaliação do Ensino Superior a Distância no Brasil. Revista Educação Temática Digital, Campinas, v.10, n.2, p. 54-70, jun. 2009.

ANGOLA. Ministério do Ensino Superior. Normas Gerais Reguladoras do Subsistema de Ensino Superior, 2014a.

Ministério do Planeamento de Desenvolvimento Territorial. 2014b

. Ministério do Ensino Superior, 2016.

- Instituto Nacional de Estatística. Censo 2014: Resultados Definitivos do Recenseamento Geral da População e da Habitação de Angola, 2014d.

BANCO MUNDIAL. Construindo o Futuro: Como é que o Ensino Superior pode contribuir para agenda de transformação económica e social de Cabo Verde. Praia, 2001.

BRASIL. Ministério da Educação/Secretaria de Educação a Distância. Referenciais de qualidade para cursos a distância no ensino superior. Brasília: MEC, 2007. Disponível em < http://portal.mec.gov.br/seed/arquivos/pdf/legislacao/refead1.pdf> Acesso em: .21 set.2015. 